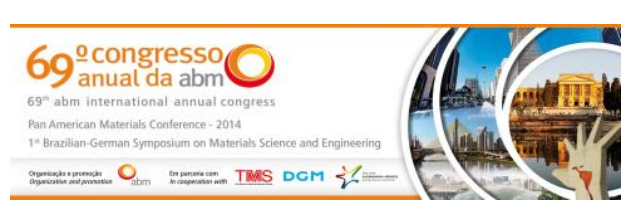

Tema: Metalurgia física e comportamento de materiais em temperaturas elevadas

\title{
RECRISTALIZAÇÃO DURANTE A SIMULAÇÃO DE LAMINAÇÃO POR ENSAIOS DE TORÇÃO DE AÇO INOXIDÁVEL FERRÍTICO ESTABILIZADO AO NIÓBIO*
}

\author{
Flávia Vieira Braga ${ }^{1}$ \\ Thompson Ávila Reis Junior ${ }^{2}$ \\ Nilton José Lucinda de Oliveira ${ }^{3}$ \\ Margareth Spangler Andrade 4
}

\section{Resumo}

Este trabalho teve como objetivo verificar a melhor condição para promoção de recristalização de um aço inoxidável ferrítico 430 , estabilizado ao $\mathrm{Nb}$, no processo de laminação à quente de acabamento. Ensaios de torção foram realizados para simular o processo de laminação em laminador Steckel, utilizando diferentes temperaturas de laminação. Ensaios interrompidos foram realizados para avaliar a recristalização entre os passes. As amostras ensaiadas foram analisadas por microscopia ótica e EBSD. Como resultado do trabalho, foram levantados os esquemas de laminação mais favoráveis para promover a recristalização. Estes esquemas poderão fornecer subsídios para estabelecimento de prática padrão industrial de laminação deste aço adequada para promover a recristalização.

Palavras-chave: Simulação de laminação; Inoxidável ferrítico; Recristalização; Nióbio; Estrias.

\section{RECRYSTALLIZATION DURING ROLLING SIMULATION TESTS TORSION OF FERRITIC STAINLESS STEEL STABILIZED WITH NIOBIUM}

\begin{abstract}
This study aimed at determining the best conditions for promoting recrystallization of a niobium stabilized ferritic stainless steel, during finishing hot rolling process. Torsion tests were performed to simulate the Steckel mill rolling process by varying the temperature of the finishing passes. Interrupted torsion tests were conducted to evaluate the recrystallization between passes. The torsion samples were analyzed by optical microscopy and EBSD. As a result of the work, favorable rolling schemes to promote recrystallization have been established. These schemes may provide subsidies for the establishing industrial hot rolling standard practice to promote recrystallization of niobium stabilized ferritic stainless steel.

Keywords: Rolling Simulation; Ferritic Stainless Steel; Recrystallization, Niobium; Ridging.

1 Física, Doutoranda, REDEMAT, UFOP, Instituto Senai de Inovação em Metalurgia e Ligas Especiais, Belo Horizonte, MG, Brasil.

2 Engenheiro da Computação, MSc. Pesquisador em Tecnologia, Instituto Senai de Inovação em Metalurgia e Ligas Especiais, Belo Horizonte, MG, Brasil.

3 Engenheiro metalurgista, MSc. Pesquisador em Tecnologia, Instituto Senai de Inovação em Metalurgia e Ligas Especiais, Belo Horizonte, MG, Brasil.

4 Física, Dr. Pesquisadora em Tecnologia, Instituto Senai de Inovação em Metalurgia e Ligas Especiais, Belo Horizonte, MG, Brasil.
\end{abstract}

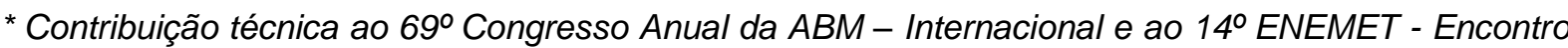
Nacional de Estudantes de Engenharia Metalúrgica, de Materiais e de Minas, 21 a 25 de julho de 2014, São Paulo, SP, Brasil.
} 


\section{INTRODUÇÃO}

Os aços inoxidáveis ferríticos são uma alternativa atrativa em substituição aos aços inoxidáveis austeníticos devido a pequena adição ou ausência de níquel. Como consequência, existe um crescente interesse no desenvolvimento e aperfeiçoamento dos aços inoxidáveis ferríticos pela indústria. Estes aços, como o do tipo ABNT 430, são amplamente utilizados em aplicações que necessitam de operações de estampagem profunda, tais como, utensílios de cozinha, cubas de pias e eletrodomésticos. Dessa maneira, é de grande importância o bom acabamento superficial [1]. Porém, estes aços podem desenvolver pequenos sulcos ou estrias na superfície da chapa, paralelamente à direção de laminação, durante a etapa de estampagem. Este fenômeno, denominado estriamento, é indesejável por prejudicar a aparência superficial do produto [1-3]. Além disso, os aços inoxidáveis ferríticos são inferiores aos aços baixo-carbono e aos austeníticos quanto à estampabilidade profunda.

Assim, várias pesquisas têm sido realizadas com a finalidade de reduzir o estriamento e melhorar a estampabilidade [4 - 7]. Segundo Oliveira et al. [7], a recristalização durante a laminação a quente contribui para a redução do estriamento e melhoria da estampabilidade. A adição de nióbio ao aço inoxidável ferrítico, como elemento estabilizador, aliada a processos controlados de laminação a quente e a frio também contribui para a produção de um material com estampabilidade superior, baixo estriamento e alto brilho quando comparados aos ferríticos não estabilizados [7].

No presente trabalho, foi investigada a melhor condição para promoção de amaciamento por recristalização durante o processo de deformação a quente de um aço ABNT 430 estabilizado ao nióbio. Para tanto, foram realizados ensaios de torção visando simular o processo de laminação a quente de acabamento, em laminador steckel, utilizando diferentes esquemas de laminação. A simulação de laminação por ensaios de torção é uma técnica adequada para estudar a laminação a quente, uma vez que permite reproduzir processos de pré-aquecimento, esquemas de deformação e taxas de resfriamento próximas às do processamento industrial. Ensaios de torção interrompidos foram realizados objetivando avaliar a recristalização entre passes. A microestrutura das amostras ensaiadas foi analisada por microscopia ótica e EBSD.

\section{MATERIAIS E MÉTODOS}

O material utilizado no presente trabalho foi um aço inoxidável ferrítico do tipo ABNT 430 estabilizado ao $\mathrm{Nb}(430 \mathrm{Nb})$, fornecido e produzido comercialmente pela Aperam South America. A Tabela 1 apresenta a composição química do aço citado.

Tabela 1: Composição química do aço inoxidável ferrítico 430Nb sob investigação. Porcentagem em peso

\begin{tabular}{ccccccccccc}
\hline Elementos & $\mathrm{C}$ & $\mathrm{Mn}$ & $\mathrm{Si}$ & $\mathrm{P}$ & $\mathrm{S}$ & $\mathrm{Cr}$ & $\mathrm{Ni}$ & $\mathrm{Al}$ & $\mathrm{Nb}$ & $\mathrm{N}_{2}$ \\
\hline $430 \mathrm{Nb}$ & 0,02 & 0,20 & 0,48 & 0,03 & 0,0005 & 16,07 & 0,18 & 0,0017 & 0,32 & $240^{*}$ \\
\hline
\end{tabular}

$\left(^{*}\right)$ Ppm

\footnotetext{
* Contribuição técnica ao 69 Congresso Anual da ABM - Internacional e ao 14ํㅡㄹ ENET - Encontro Nacional de Estudantes de Engenharia Metalúrgica, de Materiais e de Minas, 21 a 25 de julho de 2014, São Paulo, SP, Brasil.
} 


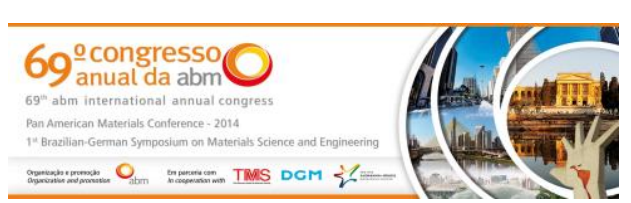

Para realização da simulação de laminação, corpos de prova de torção, com comprimento útil de $15 \mathrm{~mm}$ e diâmetro de $7 \mathrm{~mm}$, foram usinados a partir de amostras de chapas de $28 \mathrm{~mm}$ de espessura retiradas após a laminação de desbaste de tiras a quente. Os ensaios de torção a quente foram realizados em uma máquina de ensaios mecânicos INSTRON 1125, equipada com módulo de torção e célula de torque com capacidade de até 200 N.m. Uma bobina de indução eletromagnética ligada a uma fonte com controlador programável é posicionada ao redor do corpo de prova de modo que várias taxas de aquecimento e resfriamento possam ser aplicadas. Os ensaios foram conduzidos em atmosfera controlada com argônio para evitar a oxidação excessiva dos corpos de prova.

A fim de determinar faixas de temperaturas nitidamente delimitadas entre as regiões de amaciamento (recristalização e/ou recuperação), amaciamento parcial e de não amaciamento entre passes foi realizado um ensaio "visão geral" de torção a quente de múltiplos passes em resfriamento contínuo. Para tanto, o corpo de prova foi aquecido até $1200^{\circ} \mathrm{C}$ a uma taxa de $2^{\circ} \mathrm{C} / \mathrm{s}$, após permanecer nesta temperatura por $120 \mathrm{~s}$, foi resfriado a uma taxa de $1^{\circ} \mathrm{C} / \mathrm{s}$. Passes com deformações equivalentes verdadeiras de 0,2 foram aplicados a cada $30^{\circ} \mathrm{C}$, sendo que o primeiro passe foi a $1170^{\circ} \mathrm{C}$ e o último a $660^{\circ} \mathrm{C}$.

Foram realizados ensaios de torção para simular a laminação de acabamento, em laminador Steckel, do aço $430 \mathrm{Nb}$, utilizando diferentes esquemas de laminação, com o objetivo de verificar a melhor condição para promoção de amaciamento por recristalização. Nos ensaios, os corpos de prova foram aquecidos a $2^{\circ} \mathrm{C} / \mathrm{s}$, até $1050^{\circ} \mathrm{C}$ e após $120 \mathrm{~s}$, foram resfriados a uma taxa de $1^{\circ} \mathrm{C} / \mathrm{s}$ até a temperatura do primeiro passe. Um total de 5 passes de deformação foram aplicados. As deformações equivalentes foram obtidas a partir dos dados industriais do processamento do aço em estudo. A Tabela 2 mostra os esquemas de deformação e tempo entre passes, no meio do comprimento da tira, que foram utilizados na simulação de laminação de acabamento em laminador Steckel. As temperaturas de deformação utilizadas nos ensaios variaram conforme especificado na Tabela 3.

Tabela 2: Esquemas de deformação e tempo entre passes para a simulação de laminação de acabamento, do aço $430 \mathrm{Nb}$, através dos ensaios de torção

\begin{tabular}{ccccc}
\hline Passe & $\begin{array}{c}\text { Espessura } \\
\text { inicial }(\mathrm{mm})\end{array}$ & $\begin{array}{c}\text { Espessura } \\
\text { final }(\mathrm{mm})\end{array}$ & $\begin{array}{c}\text { Deformação } \\
\text { equivalente }\end{array}$ & $\begin{array}{c}\text { Tempo entre } \\
\text { passes (s) }\end{array}$ \\
\cline { 5 - 5 } & 28,4 & 19,6 & 0,43 & Corpo da tira \\
\hline 2 & 19,6 & 11,5 & 0,62 & 68 \\
\hline 3 & 11,5 & 7,1 & 0,56 & 72 \\
\hline 4 & 7,1 & 5,3 & 0,34 & 132 \\
\hline 5 & 5,3 & 4,1 & 0,30 & 25 \\
\hline
\end{tabular}

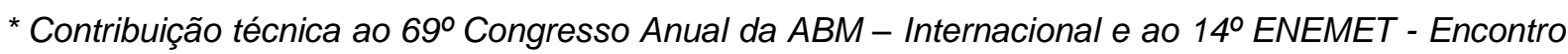
Nacional de Estudantes de Engenharia Metalúrgica, de Materiais e de Minas, 21 a 25 de julho de 2014, São Paulo, SP, Brasil.
} 


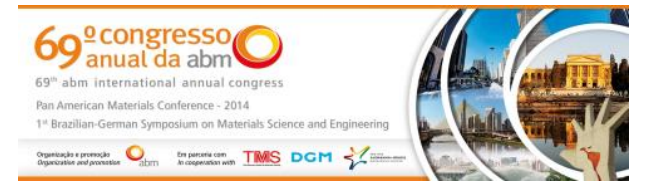

Tabela 3: Temperaturas de deformação utilizadas em cada passe de simulação de laminação de acabamento em laminador Steckel através dos ensaios de torção.

\begin{tabular}{ccccccc}
\hline \multirow{2}{*}{ Passe } & \multicolumn{6}{c}{ Temperatura do passe $\left({ }^{\circ} \mathrm{C}\right)$} \\
\cline { 2 - 7 } & Esq1 & Esq 2 & Esq3 & Esq4 & Esq5 & Esq6 \\
\hline 1 & 1050 & 1020 & 990 & 960 & 930 & 900 \\
\hline 2 & 1035 & 1005 & 975 & 945 & 915 & 885 \\
\hline 3 & 1020 & 990 & 960 & 930 & 900 & 870 \\
\hline 4 & 1005 & 975 & 945 & 915 & 885 & 855 \\
\hline 5 & 990 & 960 & 930 & 900 & 870 & 840 \\
\hline
\end{tabular}

Com o objetivo de investigar a ocorrência de recristalização entre passes, ensaios de torção a quente foram interrompidos antes do passe seguinte e os corpos de prova analisados via EBSD. A simulação de laminação de acabamento tem o total de 5 passes de deformação, dessa maneira, as interrupções foram realizadas antes do $3^{\circ}$ passe, antes do $4^{\circ}$ e antes do $5^{\circ}$ passe.

A análise metalográfica foi feita em seções longitudinais dos corpos de prova em um plano a $0,1 \mathrm{~mm}$ de profundidade em relação à superfície, a fim de obter uma largura de seção de aproximadamente $2 \mathrm{~mm}$ para que a microestrutura fosse analisada próximo à superfície destes. A preparação destas amostras foi conduzida com lixamento, polimento com pasta de diamante até $1 \mu \mathrm{m}$ e polimento em solução de sílica coloidal com granulometria de $40 \mathrm{~nm}$ por $1 \mathrm{~min}$. Em seguida, foi feita a despassivação das superfícies polidas por 60 s com uma solução de $100 \mathrm{ml}$ de água destilada, $2 \mathrm{ml}$ de ácido acético e duas gostas de alumina coloidal. Após, foi realizado ataque colorante à temperatura de $75^{\circ} \mathrm{C}$ por 105 s utilizando a solução de $110 \mathrm{ml}$ de água destilada, $12 \mathrm{ml}$ de $\mathrm{H}_{2} \mathrm{SO}_{4}, 4 \mathrm{ml}$ de $\mathrm{HF}$ e 5 gotas de $\mathrm{HNO}_{3}$.Um microscópio óptico com luz polarizada foi utilizado, sendo obtidas imagens coloridas nas quais grãos com a mesma tonalidade de cor correspondem a orientações cristalográficas próximas.

A preparação das amostras para EBSD foi realizada da mesma maneira que a preparação para a microscopia ótica até a etapa de polimento. Posteriormente, as amostras foram polidas com sílica coloidal por cerca de 40 minutos. Os mapas de EBSD foram obtidos em um microscópio Fei Quanta 650 Feg/ Oxford High Speed detector Nordlys Max 2 instalado no LNNano/LME. A tensão de aceleração utilizada foi de $20 \mathrm{kV}$ e distância de trabalho de $18 \mathrm{~mm}$.

\section{RESULTADOS E DISCUSSÃO}

A curva de tensão equivalente em função da deformação para o ensaio de "visão geral" é mostrada na Figura 1. De acordo com a forma das curvas, acima da temperatura de $990^{\circ} \mathrm{C}$ o material sofreu apenas amaciamento dinâmico por recuperação. O aumento nos níveis de tensão de um passe para o seguinte se deve à queda da temperatura, com consequente aumento da resistência à deformação.

\footnotetext{
* Contribuição técnica ao 69ำ Congresso Anual da ABM - Internacional e ao 14ํㅡㄹ ENEMET - Encontro Nacional de Estudantes de Engenharia Metalúrgica, de Materiais e de Minas, 21 a 25 de julho de 2014, São Paulo, SP, Brasil.
} 


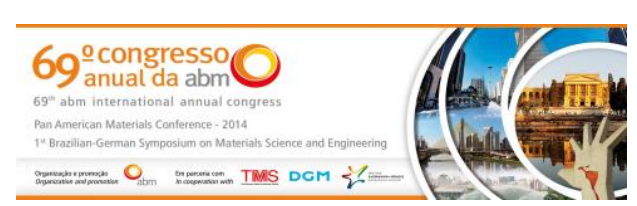

A curva de tensão equivalente média em função do inverso da temperatura absoluta é apresentada na Figura 2. Podem-se observar, nesta curva, duas mudanças de comportamento no processo de amaciamento do material, uma em torno de $1000^{\circ} \mathrm{C}$ e outra próxima de $900^{\circ} \mathrm{C}$, indicada pelas variações de inclinação das retas.

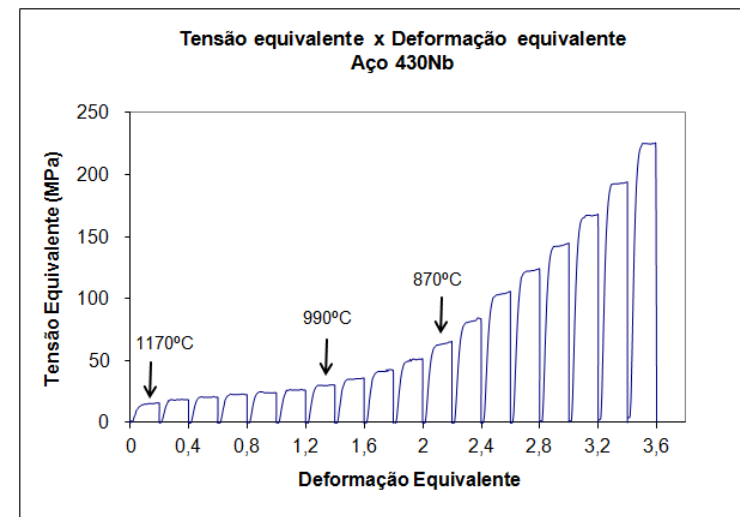

Figura 1: Tensão equivalente em função da deformação equivalente para 0 ensaio de "visão geral" de torção a quente do aço 430Nb.

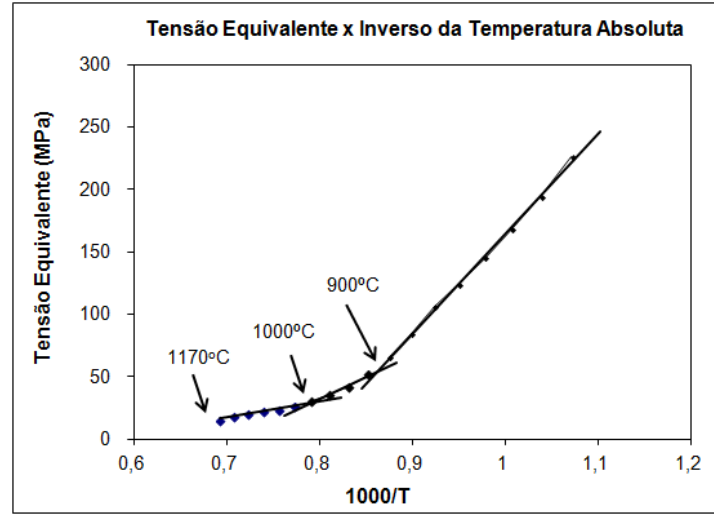

Figura 2: Tensão equivalente média em função do inverso da temperatura absoluta para o ensaio de "visão geral" de torção a quente do aço $430 \mathrm{Nb}$.

As análises das Figuras 1 e 2 sugerem que o amaciamento dinâmico do material, em temperaturas acima de $1000^{\circ} \mathrm{C}$, se dá por recuperação. Na região de transição, entre $1000^{\circ} \mathrm{C}$ e $900^{\circ} \mathrm{C}$, ocorreria recuperação estática e/ou recristalização estática. Abaixo de $900^{\circ} \mathrm{C}$ não ocorre nenhum mecanismo de amaciamento indicando um aumento na taxa de encruamento.

Os resultados apresentados nas Figuras 1 e 2 embasaram a seleção das temperaturas de deformação dos esquemas apresentados na Tabela 2. Dessa maneira, a faixa de temperatura de laminação mais provável para que o amaciamento por recristalização estática aconteça está entre 900 e $1000^{\circ} \mathrm{C}$. Os esquemas 3, 4 e 5 citados na Tabela 2 se encontram nessa faixa de temperatura. Apesar de os esquemas 1,2 e 6 estarem fora dessa faixa, os mesmos foram testados para efeitos de comparação.

As curvas de tensão equivalente em função da deformação equivalente para os esquemas de simulação de laminação de acabamento são mostrados nas Figuras 3 e 4. Conforme o formato das curvas para os esquemas 1 e 2 (Figura $3 a$ e 3b), o amaciamento se deu por recuperação dinâmica nos primeiros passes. Pode-se também observar a ocorrência de amaciamento estático entre passes, pois a tensão de escoamento de um determinado passe é menor que a tensão máxima do passe anterior. No entanto, não é possível assegurar o tipo de amaciamento estático ocorrido pela análise das curvas.

Nas Figuras 4a, 4b, 4c e 4d, a forma das curvas indica que não houve amaciamento dinâmico durante a deformação. Entretanto, pode ser observada a ocorrência de amaciamento estático. A ocorrência de recristalização estática pode ser evidenciada pela acentuada diferença da tensão de escoamento entre um passe e o passe subsequente, ou seja, quando a tensão de escoamento de um passe é menor que a tensão máxima do passe anterior. Este fato pode ser observado nos quatro esquemas mostrados na Figura 4. Porém, a ocorrência de amaciamento por recristalização estática pode ser confirmado apenas por EBSD.

\footnotetext{
* Contribuição técnica ao $69^{\circ}$ Congresso Anual da ABM - Internacional e ao 14ํㅡㄹ ENEMET - Encontro Nacional de Estudantes de Engenharia Metalúrgica, de Materiais e de Minas, 21 a 25 de julho de 2014, São Paulo, SP, Brasil.
} 

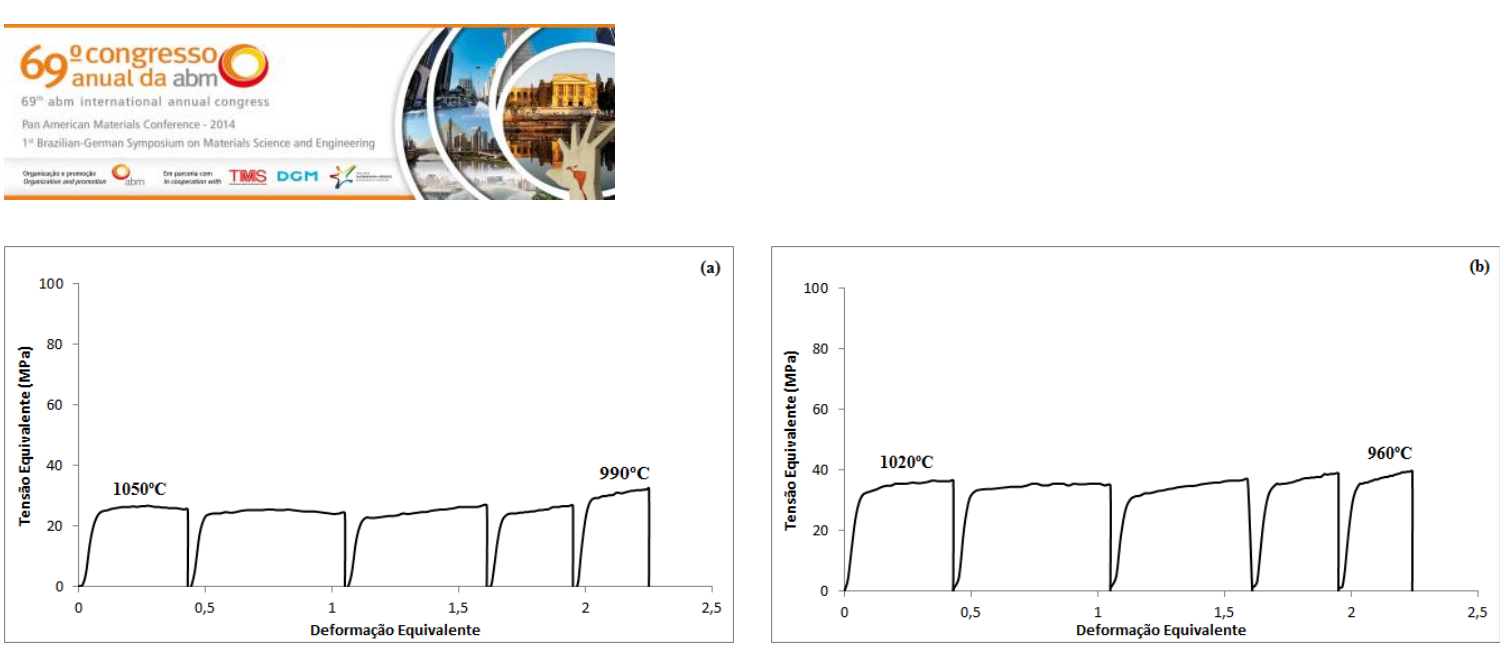

Figura 3: Curvas de tensão equivalente em função da deformação equivalente para os ensaios de simulação de laminação de acabamento: (a) esquema 1 e (b) esquema 2. As temperaturas indicadas nos gráficos se referem às temperaturas de primeiro e último passes.
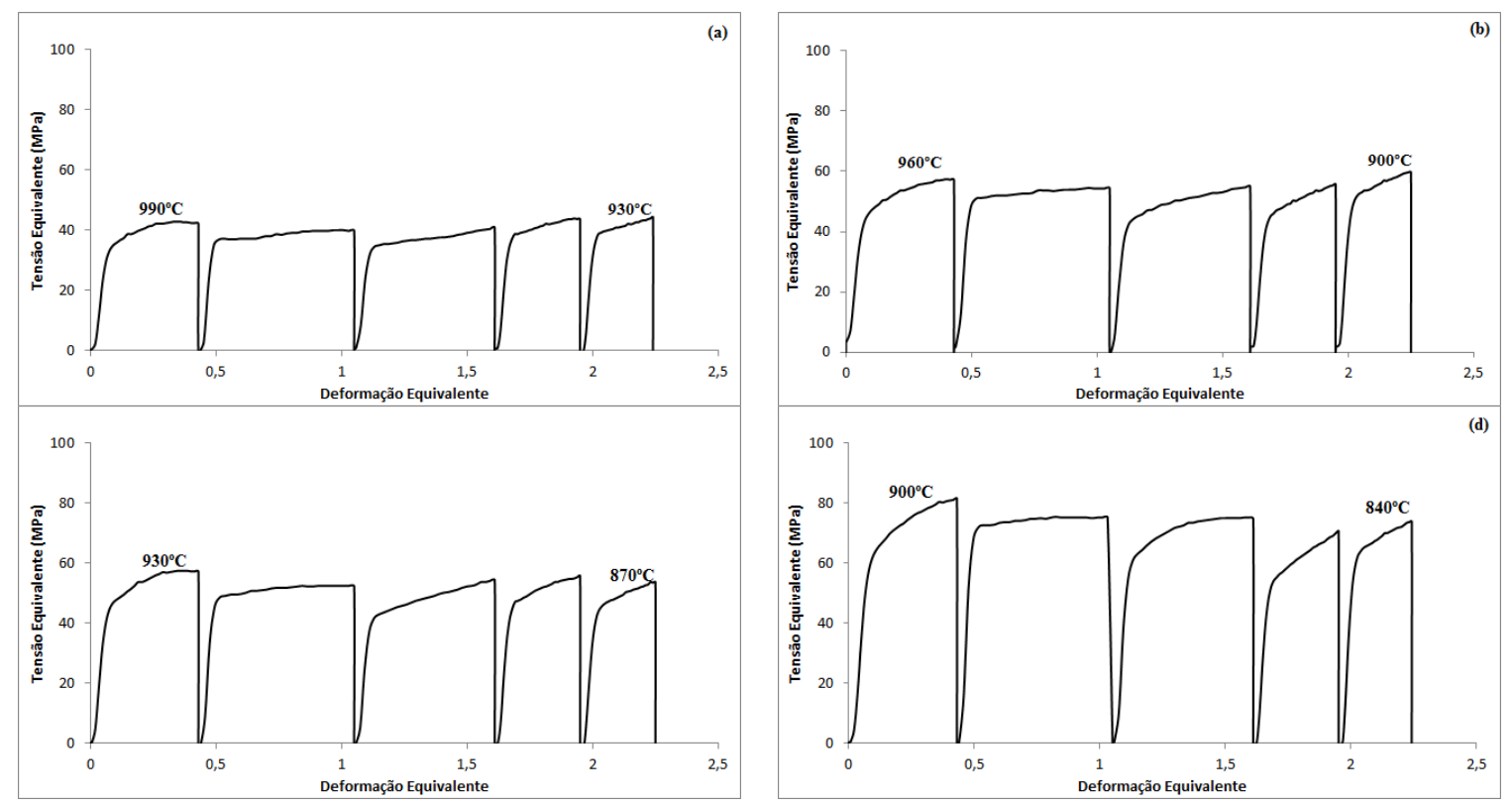

Figura 4: Curvas de tensão equivalente em função da deformação equivalente para os ensaios de simulação de laminação de acabamento: (a) esquema 3, (b) esquema 4, (c) esquema 5 e (d) esquema 6. As temperaturas indicadas nos gráficos se referem às temperaturas de primeiro e último passes.

As micrografias óticas dos corpos de prova são mostradas nas Figuras 5 e 6 . Nas microestruturas das amostras do esquema 1 e do esquema 2 (Figuras $5 a$ e $5 b$ ) os grãos são maiores e apresentam forma de deformação acumulada, com presença marcante de subgrãos, o que indica o processo de recuperação.

No entanto, as micrografias da Figura 6 apresentam microestruturas com evidências de recristalização estática. Pode-se observar que as microestruturas dos esquemas 4,5 e 6 (Figura 6b, c e d, respectivamente), se mostram mais fragmentadas, com grãos de tamanho menor do que na micrografia do esquema 3 (Figura 6a). Este fato pode ser uma evidência de que a fração recristalizada aumentou com a diminuição da temperatura de deformação.

As microestruturas com evidências de recristalização não apresentam grãos equiaxiais e livres de deformação. Durante a simulação de laminação de acabamento, em laminador Steckel, foram dados 5 passes de deformação, dessa maneira, a microestrutura pode ter recristalizado num intervalo entre passes e se deformado num passe posterior.

É importante salientar que o laminador Steckel é um laminador reversível, portanto, os tempos entre passes variam muito dependendo da posição a ser considerada ao

\footnotetext{
* Contribuição técnica ao $69^{\circ}$ Congresso Anual da ABM - Internacional e ao 14ํㅡㄹ ENEMET - Encontro Nacional de Estudantes de Engenharia Metalúrgica, de Materiais e de Minas, 21 a 25 de julho de 2014, São Paulo, SP, Brasil.
} 


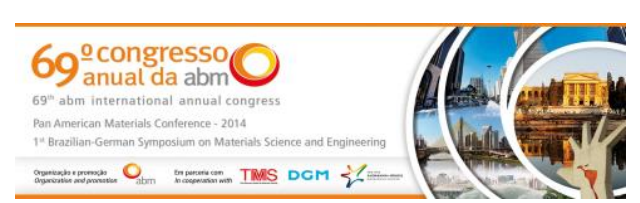

longo do comprimento da tira (cabeça, corpo e cauda). Neste trabalho, o tempo entre passes variou entre 25 e 132s, dessa maneira, é possível a formação e crescimento de novos grãos. O tempo entre passes é mínimo em laminadores de trem contínuo (Tandem) devido à alta velocidade de processo [7].

Para que a recristalização estática ocorra é necessário que em determinado passe haja acúmulo de encruamento. Nos esquemas 4, 5 e 6, podemos observar que nos passes 3, 4 e 5 (Figura 4b, c e d) houve acúmulo de deformação, força motriz para que a recristalização estática pudesse ocorrer entre os passes 3 e 4 e entre os passes 4 e 5.
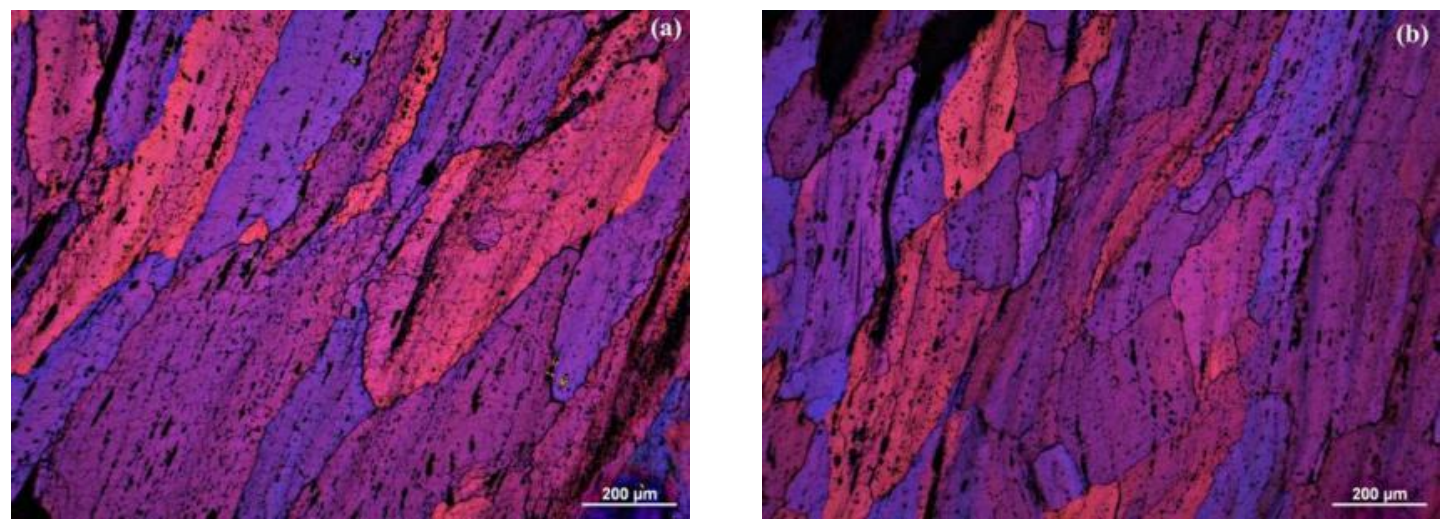

Figura 5: Imagens por microscopia óptica com ataque colorante e luz polarizada das amostras dos ensaios de simulação de laminação de acabamento: (a) esquema 1 e (b) esquema 2.
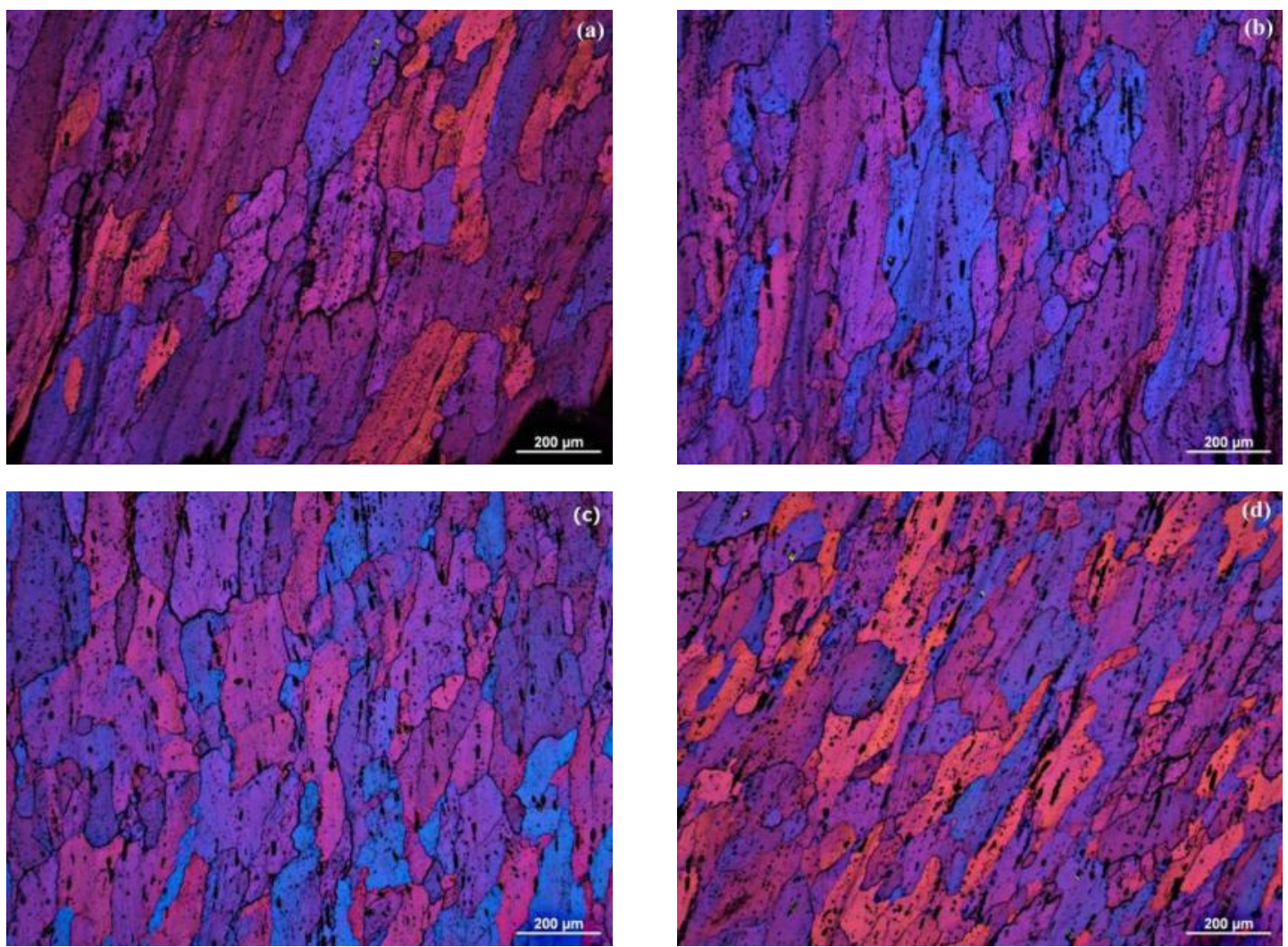

Figura 6: Imagens por microscopia óptica com ataque colorante e luz polarizada das amostras dos ensaios de simulação de laminação de acabamento: (a) esquema 3, (b) esquema 4, (c) esquema 5 e (d) esquema 6.

\footnotetext{
* Contribuição técnica ao $69^{\circ}$ Congresso Anual da ABM - Internacional e ao 14ํㅡㄹ ENEMET - Encontro Nacional de Estudantes de Engenharia Metalúrgica, de Materiais e de Minas, 21 a 25 de julho de 2014, São Paulo, SP, Brasil.
} 
A partir dos resultados das curvas de tensão $\mathrm{x}$ deformação e das micrografias óticas, foram selecionados os esquemas 4 e 5 para investigação da ocorrência de recristalização entre passes. Foram realizados ensaios de torção interrompidos e as amostras analisadas via EBSD. Foi utilizada a desorientação acima de $10^{\circ}$ como critério para marcar os contornos de grão.

As Figuras $7 \mathrm{a}$ e $7 \mathrm{~b}$, mostram os mapas de cores da combinação dos três ângulos de Euler das amostras dos esquemas 4 e 5 interrompidos antes do 3 o passe. Durante estes ensaios, os corpos de prova de torção receberam dois passes de deformação e foram resfriados imediatamente antes do $3 \div$ passe. Pode-se observar a formação de novos grãos. A microestrutura dos esquemas 4 e 5 são similares.

A microestrutura das amostras dos ensaios interrompidos antes do $4^{0}$ passe (Figura 8) para ambos os esquemas já se mostra mais fragmentada comparada à das amostras dos ensaios interrompidos antes do 30 passe. Além disso, os grãos se apresentam com contorno de alto ângulo. Estes fatos comprovam as evidências de amaciamento por recristalização estática.

As Figuras 9a e 9b mostram os mapas de cores da combinação dos três ângulos de Euler das amostras dos ensaios interrompidos antes do $5^{\circ}$ passe. Pode-se observar formação de novos grãos e grãos deformados. Neste caso, as amostras acumularam quatro passes de deformação, portanto, grãos recristalizados anteriormente aparecem deformados após o $4^{\circ}$ passe de deformação. A microestrutura referente à amostra do esquema 5 se mostra mais fragmentada comparada à amostra do esquema 4, de acordo com as Figuras 9a e 9b respectivamente.

Os mapas de cores da combinação dos três ângulos de Euler das amostras dos ciclos completos para os esquemas 1 e 4 são apresentados nas Figuras 10a e 10b respectivamente. Vale ressaltar o refinamento da microestrutura da amostra do esquema 4 quando comparada à da amostra do esquema 1 . O refinamento da estrutura durante a etapa de laminação a quente é de grande importância para minimizar o problema de estriamento em aços inoxidáveis ferríticos do tipo ABNT 430. Visto que a recristalização, em muitos casos, modifica de forma significativa a textura dentro do material por meio da quebra da textura de solidificação [7].

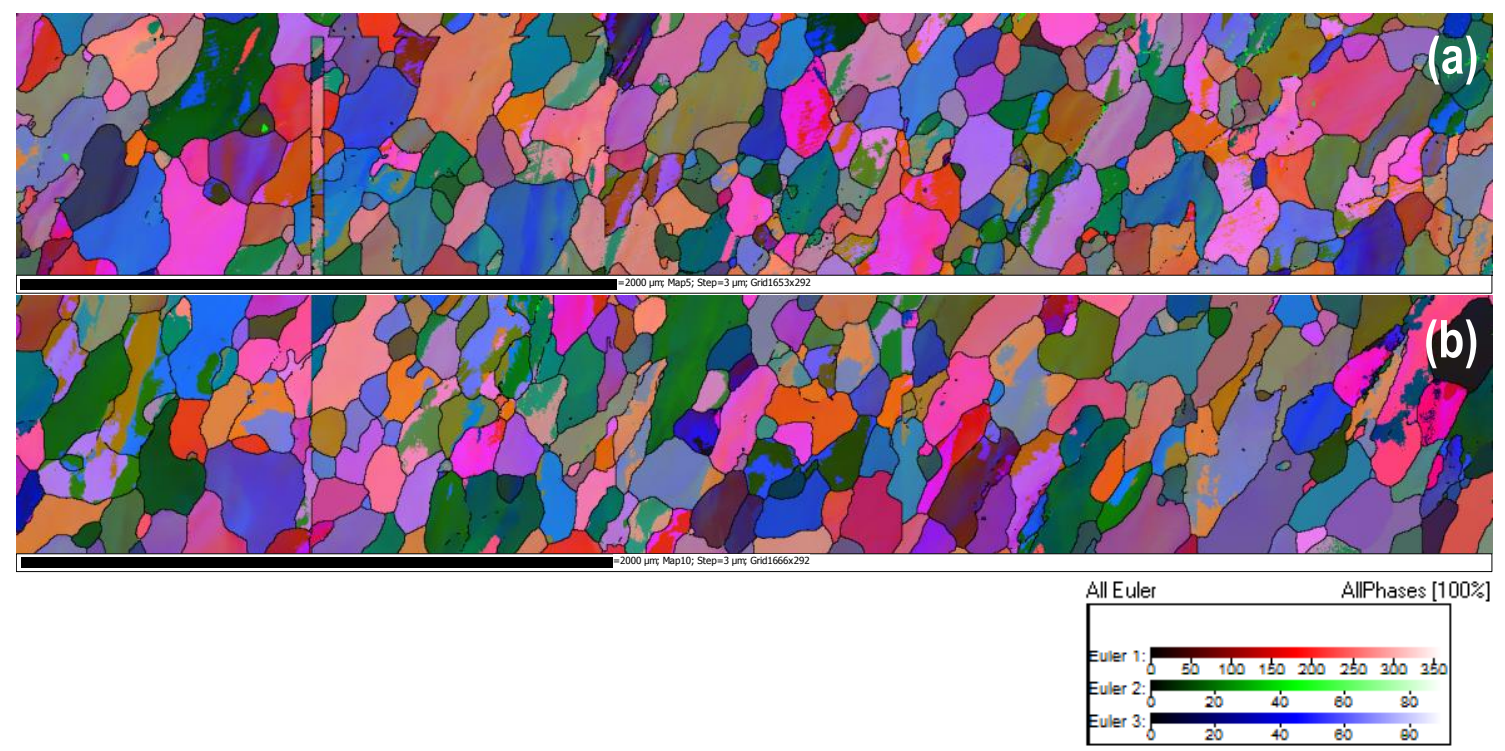

Figura 7: Mapas de EBSD das amostras dos ensaios interrompidos antes do 30 passe para $\circ$ (a) esquema 4 e (b) esquema 5.

* Contribuição técnica ao 69 Congresso Anual da ABM - Internacional e ao 14ํㅡㄹ ENEMET - Encontro Nacional de Estudantes de Engenharia Metalúrgica, de Materiais e de Minas, 21 a 25 de julho de 2014, São Paulo, SP, Brasil. 

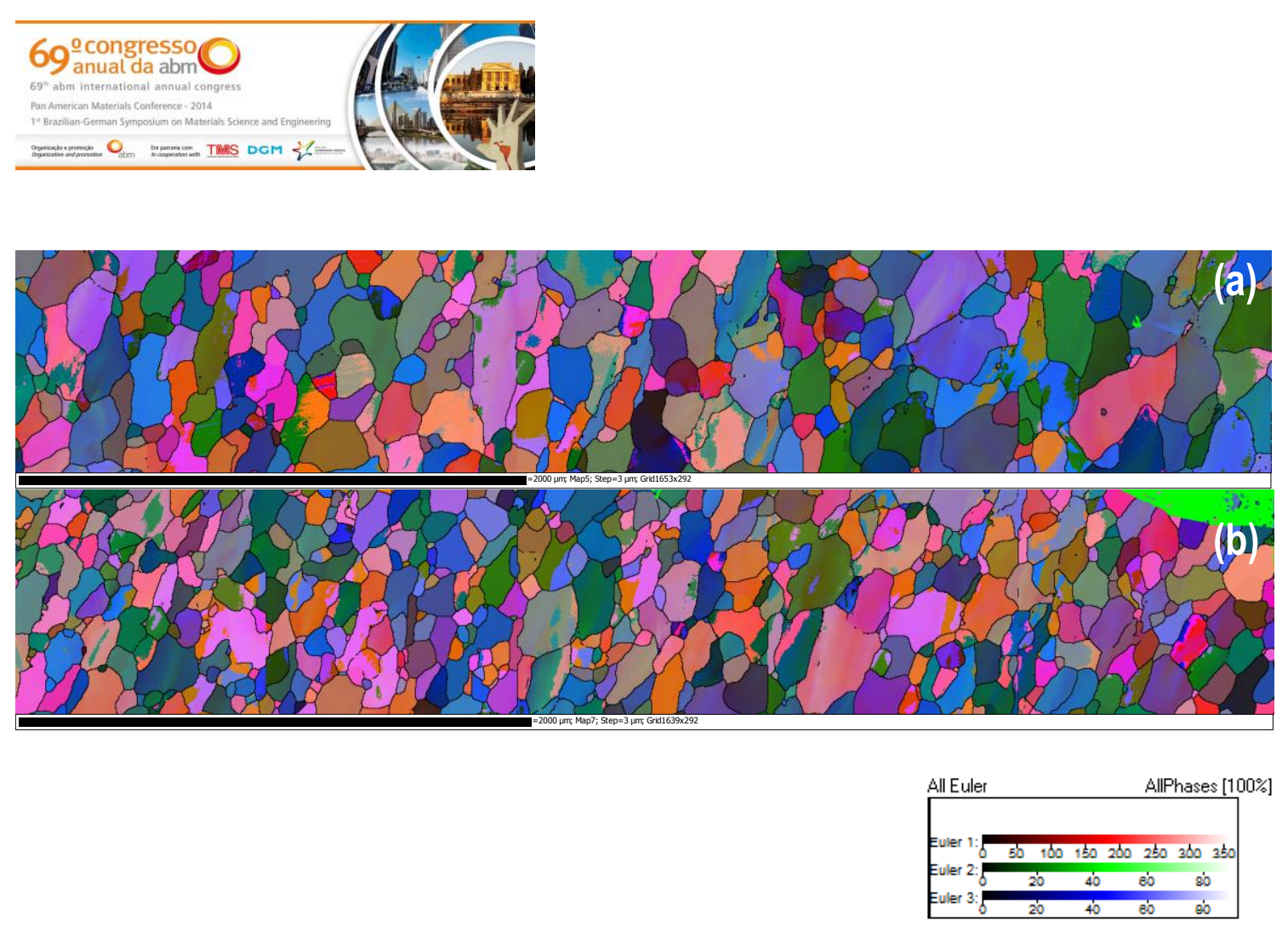

Figura 8: Mapas de EBSD das amostras dos ensaios interrompidos antes do 4ํㅜ passe para o (a) esquema 4 e (b) esquema 5.

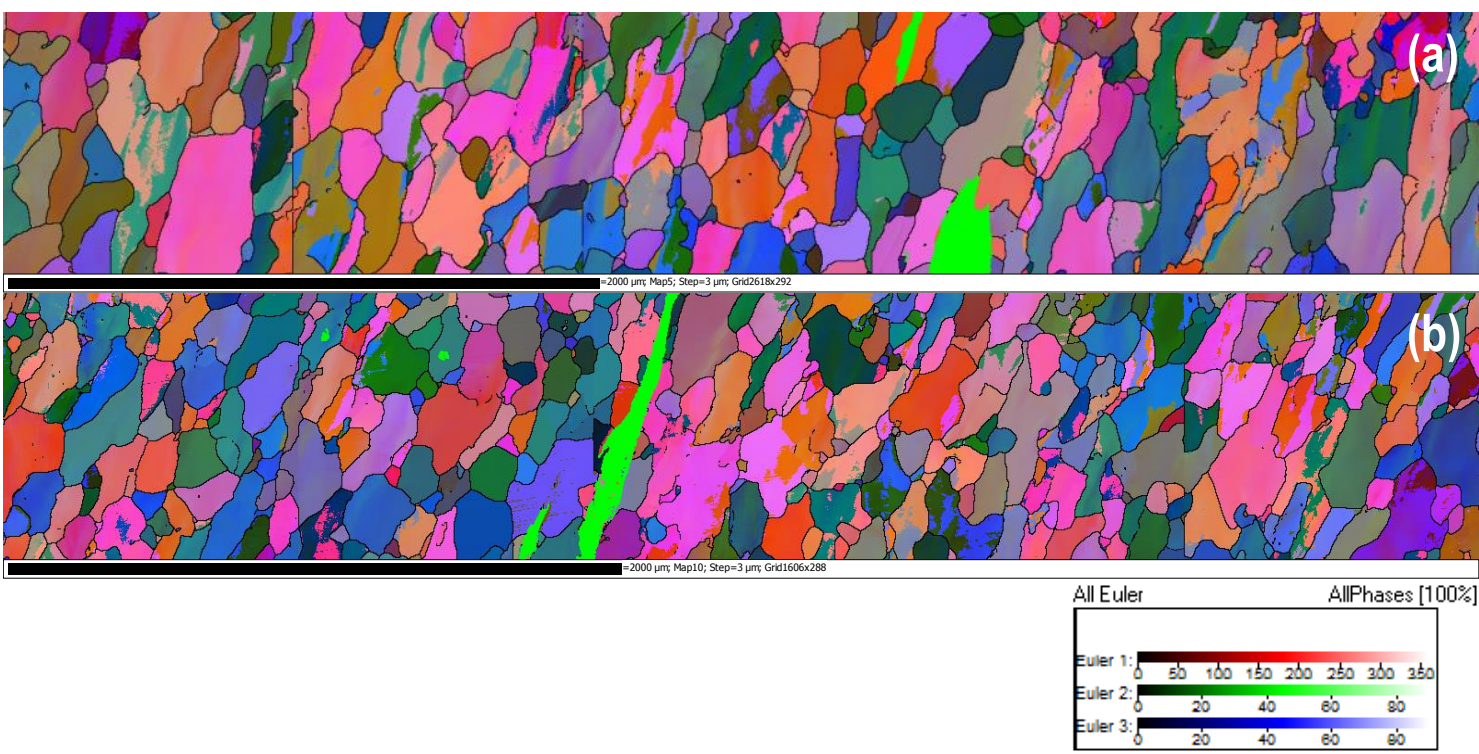

Figura 9: Mapas de EBSD das amostras dos ensaios interrompidos antes do $5^{\circ}$ passe para o (a) esquema 4 e (b) esquema 5.

\footnotetext{
* Contribuição técnica ao 69ํㅡㄹ Congresso Anual da ABM - Internacional e ao 14ํㅡㄹ ENEMET - Encontro Nacional de Estudantes de Engenharia Metalúrgica, de Materiais e de Minas, 21 a 25 de julho de 2014, São Paulo, SP, Brasil.
} 

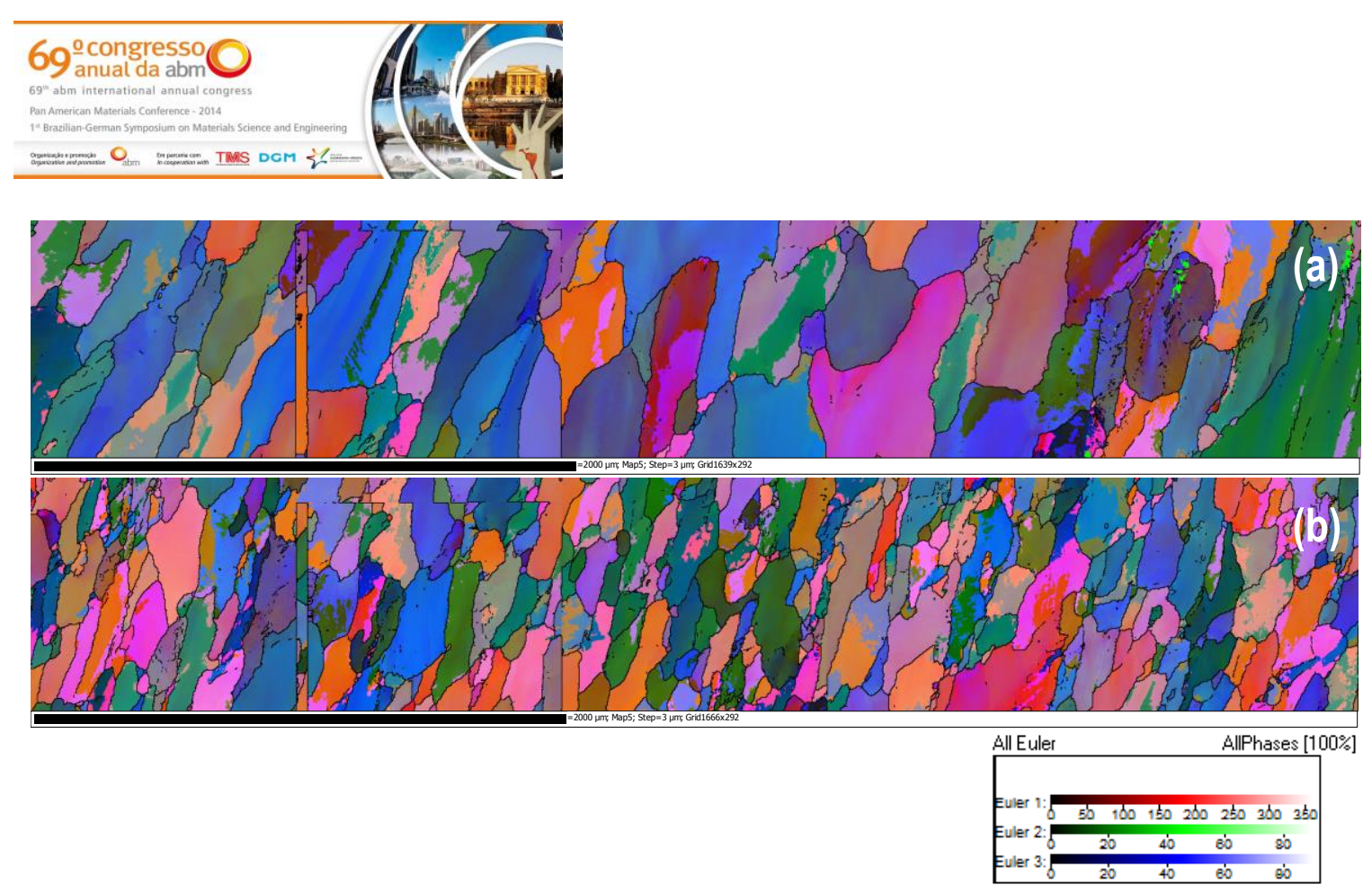

Figura 10: Mapas de EBSD das amostras dos ciclos completos para o (a) esquema 1 e (b) esquema 4.

\section{CONCLUSÃo}

$\checkmark$ Os resultados do ensaio com deformações em resfriamento contínuo permitiram estabelecer que a faixa de temperaturas mais favorável para ocorrer recristalização do aço inoxidável ferrítico estabilizado ao Nióbio, é de 1000 a $900^{\circ} \mathrm{C}$.

$\checkmark$ Acima de $1000^{\circ} \mathrm{C}$ o mecanismo de amaciamento é por recuperação dinâmica, não havendo energia disponível para recristalização estática. Abaixo de $900^{\circ} \mathrm{C}$ ocorre encruamento acumulado entre os passes, o que resulta em alta energia deformação, mas a recristalização é dificultada devido às baixas temperaturas. $\mathrm{Na}$ faixa estabelecida, ocorre a combinação de encruamento e temperatura adequados para promover a recristalização entre passes.

$\checkmark$ Foi confirmado que ocorre recristalização entre passes no aço inoxidável ferrítico estabilizado ao Nióbio nessa faixa de temperaturas, por meio de ensaios de simulação de laminação de acabamento em laminador Steckel. Os esquemas mais favoráveis para a recristalização foram os com início da laminação de acabamento em 960 e $930 \stackrel{\circ}{\circ}$.

$\checkmark$ As técnicas de análise por microscopia óptica, após ataque colorante e uso de luz polarizada, por EBSD, combinadas com a análise das curvas de torção foram adequadas para verificar a ocorrência de recristalização estática entre os passes da laminação de acabamento em Steckel.

\section{Agradecimentos}

Os autores agradecem à Companhia Brasileira de Mineração e Metalurgia-CBMM pelo apoio financeiro e discussões, à Aperam South America pelo apoio técnico e fornecimento de amostras, ao Dr. Marco Antônio da Cunha pelas discussões. MSA e FVB agradecem ao CNPq e à Capes pelas bolsas concedidas.

\footnotetext{
* Contribuição técnica ao $69^{\circ}$ Congresso Anual da ABM - Internacional e ao 14ํㅡㄹ ENEMET - Encontro Nacional de Estudantes de Engenharia Metalúrgica, de Materiais e de Minas, 21 a 25 de julho de 2014, São Paulo, SP, Brasil.
} 


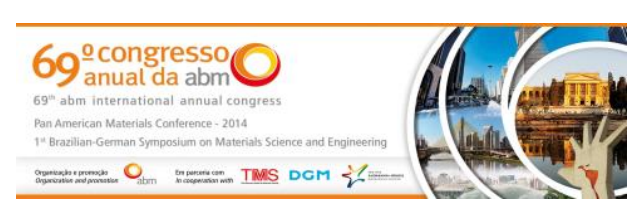

\section{REFERÊNCIAS}

1 Brochu M, Yokota T, Satoh S. Analysis of Grain Colonies in Type 430 Ferritic Stainless Steels by Electron Back Scattering Diffraction (EBSD). ISIJ International, 1997; 37: 872 $-877$.

2 Takechi $\mathrm{H}$, Kato H, Sunami T, Nakayama T. The Mechanism of Ridging Formation in 17\%-Chromium Stainless Steel Sheets. Transactions JIM, Japan, 1967; 8: 233-239.

3 Shin H, An K, Park SH, Lee DN. The Effect of Texture on Ridging of Ferritic Stainless Steel. Acta Materialia, 2003; 51: 4697-4706.

4 Wei D, Lai-Zhu J, Quan-She S, Zhen-Yu L, Xin Z. Microstructure, Texture, and Formability of $\mathrm{Nb}+\mathrm{Ti}$ Stabilized High Purity Ferritic Stainless Steel. Journal of Iron And Steel Research, 2010; 17: 47-52.

5 Yan, H.; BI, H.; LI, X.; XU, Z. Microstructure, texture and grain boundaries character distribuition evolutuion of ferritic stainless steel during rolling process. Journal of Materials Processing Technology, vol. 209, p.2 627-2631, 2009.

6 Gao F, Liu Z. Development of very tough ferritic stainless steels by improving the recrystalixed microstructure. Materials Science Forum, vol. 753, p. 526-529, 2013.

7 Oliveira TR, Silva RCR, Alcântara CM, et al. Aço inoxidável ferrítico topo ASTM 430 para estampagem profunda, com alto brilho e isento de estriamento. 68은 Congresso Anual da Associação Brasileira de Metalurgia e Materiais - ABM, Julho 2013, Belo Horizonte, Brasil.

* Contribuição técnica ao 69ำ Congresso Anual da ABM - Internacional e ao 14ํㅡㄹ ENEMET - Encontro Nacional de Estudantes de Engenharia Metalúrgica, de Materiais e de Minas, 21 a 25 de julho de 2014, São Paulo, SP, Brasil. 